\title{
Surgical Management of Fulminant Diverticulitis
}

\author{
Edward Kwon · T. Browder · John Fildes
}

Published online: 21 December 2013

(C) Springer Science + Business Media New York 2013

\begin{abstract}
The optimal management of fulminant or complicated diverticulitis is the subject of debate in recent literature. The most common management strategy remains resection and end colostomy or Hartmann's procedure, first introduced in the 1940s, despite the introduction of more current approaches supported by decreased morbidity and mortality by various studies. The purpose of this paper is to provide a review of the strategies described for the management of fulminant diverticulitis and the most recent evidence available to support these approaches. We discuss the advantages and disadvantages of the Hartmann's procedure approach, as well as the most current management strategies, and offer both citation and review of relevant recent studies.
\end{abstract}

Keywords Diverticulitis - Complicated diverticulitis . Fulminant diverticulitis · Hartmann's procedure · Colon perforation - Acute care surgery

\section{Introduction}

Diverticular disease of the colon is a relatively common finding in developed Western countries, with a prevalence of

This article is part of the Topical Collection on Acute Care Surgery.

E. Kwon $(\bowtie) \cdot T$. Browder · J. Fildes

Division of Acute Care Surgery, Department of Surgery, University of Nevada School of Medicine, 2040 West Charleston

Blvd Ste 302, Las Vegas, NV 89102, USA

e-mail: ekwon@medicine.nevada.edu

T. Browder

e-mail: tbrowder@medicine.nevada.edu

J. Fildes

e-mail: jfildes@medicine.nevada.edu approximately $10 \%$ in people younger than 40 years of age to greater than $60 \%$ in people older than 80 years [1-3]. While approximately $75-80 \%$ of people with colonic diverticulosis will remain asymptomatic throughout their lifetime, the number of patients requiring medical treatment appears to be increasing [4, 5]. Of the patients who are hospitalized for complications of diverticular disease of the colon, approximately 10-20\% will require urgent surgical intervention [6]. There are numerous complications associated with diverticular disease that may merit surgical treatment, including bleeding (5-30\%), obstruction (8-10\%), fistulae (10-20\%), and fulminant/perforated diverticulitis (4-15\%) [7, 8]. While the surgical management of the above complications is well established, there is significant debate in the optimal treatment of perforated/fulminant diverticulitis.

\section{Perforated Diverticulitis}

The term "perforated diverticulitis" is redundant, as diverticulitis implies perforation of the colonic wall with associated inflammation. It is the degree or severity of perforation that dictates the definitive management of diverticulitis. The diagnosis and severity of diverticulitis is often determined with clinical history/examination aided by radiographic imaging, especially computed tomography (CT) with IV/PO/rectal contrast, which has been found to have a sensitivity and specificity of approximately 97 and $98 \%$, respectively [9-11].

The Hinchey classification, first described in 1978, is a commonly used scale for scoring the severity of perforation (see Table 1) [12]. Hinchey classes 0 and 1 describe uncomplicated diverticulitis, which is most often amenable to medical treatment with the appropriate antibiotics and bowel rest, and occasionally percutaneous drainage of 
Table 1 Hinchey classification of acute diverticulitis (data from Hinchey et al. [12])

\begin{tabular}{ll}
\hline Stage 1 & Pericolic abscess or phlegmon \\
Stage 2 & Pelvic/intraabdominal/distant abscess \\
Stage 3 & Purulent peritonitis \\
Stage 4 & Feculent peritonitis \\
\hline
\end{tabular}

larger abscesses. Class 2 diverticulitis is also often amenable to percutaneous drainage and non-operative management, although depending on the size of the abscess and accessibility, it may require operative intervention. Hinchey classes 3 and 4 describe fulminant forms of diverticulitis, representing purulent and feculent peritonitis, respectively, and nearly always require surgical intervention [13]. The surgical management of Hinchey class 3 and 4 diverticulitis has evolved over time and the optimal operation is the subject of numerous studies.

\section{Hartmann's Procedure}

Historically, the management of perforated diverticulitis was described as a three-stage procedure with initial diversion, followed by resection, and finally by restoration of continuity $[14,15]$. The three-stage operation has since been replaced by the two-stage Hartmann's procedure and is the most common operation for emergent cases of complicated diverticulitis, used in $54-61 \%$ of cases [16, 17]. Hartmann's procedure consists of resection of the diseased colon with creation of an end colostomy and a blind rectal pouch with eventual reversal of the colostomy. The rationale for the two-stage approach is the elimination of the source of pathology and avoidance of an anastomosis in the presence of infection and inflammation, theoretically decreasing the risk of an anastomotic leak. However, diverting surgeries such as Hartman's procedure in Hinchey class 3 and 4 diverticulitis are associated with a mortality of approximately 6 and $35 \%$, respectively [18]. Given the relatively high mortality associated with diverting procedures, recent studies have challenged the dangers of creating an anastomosis during surgery for complicated diverticulitis and the need for a two-stage procedure. A recent meta-analysis of studies evaluating the mortality rates for Hartmann's-type procedures compared to primary resection and anastomosis found a pooled mortality of 21 versus $9.7 \%$, supporting the lack of evidence for increased safety with a two-stage procedure [19]. Hartmann's procedure also mandates a second operation in order to restore colonic continuity, although approximately $30 \%$ of patients who undergo a Hartmann's procedure are never reversed [20-22]. The mortality and complication rate of an operation to reverse a Hartmann's procedure is significant and reported in the literature to be as high as $44 \%$ [23-26]. Despite the lack of evidence for increased safety of a two-stage procedure in the setting of complicated diverticulitis, it currently remains the most common operation and may be the best option in certain patient populations, especially those on immunosuppressive therapy and patients who are hemodynamically unstable due to the speed of the operation and lack of anastomoses [27•, 28, 29].

\section{Primary Resection and Anastomosis}

The primary resection and anastomosis approach is gaining in popularity as an alternative to the previous gold standard of a Hartmann's procedure for the management of Hinchey class 3 and 4 diverticulitis. This is due to the growing body of literature supporting the high complication rate associated with Hartmann's procedure and eventual stoma reversal. Aside from the relatively high mortality associated with Hartmann's procedure, anastomotic leak rates post-reversal of up to $30 \%$ and wound infection rates of $24 \%$ have been reported [23, 30, 31]. Comparatively, findings from a systematic review of the literature found that primary resection and anastomosis are associated with mortality, which is nearly half of Hartman's procedure and a wound infection rate of $9 \%$ and a leak rate of $14 \%$ [23]. A recent review of the NSQIP database found similar outcomes when comparing patients who underwent Hartmann's procedure versus primary anastomosis, with mortality of 7.3 versus $4.6 \%$ and wound infection rates of 19.7 versus $17.9 \%$ [24••]. Concern regarding increased anastomotic leaks with primary anastomosis in the presence of an unprepped colon has been an argument for proponents of Hartmann's procedure in the past, however, this has been found to be unsupported by the literature. In trauma patients, primary repair and anastomosis of the colon in an unprepped bowel has been shown to be a safe option [3237]. Additionally, in elective cases of colon and rectal surgery, primary anastomoses in prepped versus unprepped bowels have not shown any statistical differences in wound infection, anastomotic leakage, or intraabdominal abscess rates, and at least one recent, randomized clinical trial suggests that morbidity may be decreased in the absence of preoperative bowel preparation $[34,35]$. An alternative to mechanical bowel preparation in the emergent setting of perforated diverticulitis is on-table colonic lavage, which may facilitate handling of the colon and decrease the amount of spillage intraoperatively, thus decreasing the likelihood of infection. On-table colonic lavage with primary anastomosis has been shown to be an effective strategy for decreasing fecal load in both emergent colon resections, as well as for less emergent cases of obstructing 
and partially obstructing colonic lesions [34, 38, 39]. Another consideration with performing a primary anastomosis is that of proximal diversion. The creation of a diverting ileostomy is a relatively common practice amongst colorectal surgeons performing low colonic resections and high-risk anastomoses, and has been demonstrated to significantly decrease the symptomatic leak rate in their patient population [40]. Regarding complicated diverticulitis, there are several studies demonstrating the decreased complications of both primary anastomosis with and without proximal diversion, compared to Hartmann's

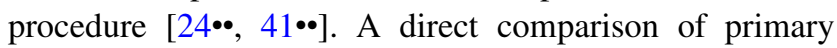
anastomosis with proximal diversion and without in the setting of acute diverticulitis has yet to be studied, although there appeared to be a trend in decreased complication when utilizing proximal diversion in two separate reviews of the NSQIP database by Tadlock et al. [24••] and Gawlick [41••]. In contrast to Hartmann's reversal, loop ileostomy reversal rates approach $92 \%$, and the overall combined mortality of Hartmann's procedure and reversal versus primary anastomosis with proximal diversion and reversal is 19.6 versus $9.9 \%$ [23, 42]. Although there is a lack of randomized control studies to suggest that primary anastomosis with proximal diversion improves outcomes, proximal diversion seems to be prudent given the available evidence. While the majority of studies comparing Hartmann's procedure to primary anastomosis are retrospective and therefore may be subject to selection bias, a recent randomized clinical trial demonstrated that both procedures were statistically equivalent in morbidity and mortality of patients with Hinchey 3 and 4 diverticulitis, with a greater stoma reversal rate, decreased serious complications, and overall lower hospital costs with primary anastomosis and proximal diversion $[43 \bullet \bullet]$.

\section{Laparoscopic Peritoneal Lavage}

Laparoscopic peritoneal lavage for the initial management of complicated diverticulitis involves a diagnostic survey of the abdomen, followed by irrigation, placement of drains within the abdomen, and antibiotic therapy. First described in 1996 by O'Sullivan et al. [44], there is an increasing interest in this modality as an alternative to the traditional Hartmann's procedure for complicated diverticulitis. The advantages to laparoscopic peritoneal lavage as the initial surgical procedure are cited as the avoidance of the risks of colon resection in the acute setting, avoidance of an ostomy, and the ability to perform an elective colon resection in a non-hostile environment if found to be necessary. A systematic review of the literature surrounding peritoneal lavage and drainage by Toorenvliet et al. [45] revealed a lack of randomized control trials. However, the authors found that the current evidence suggests lavage as a safe alternative in treating acute complicated diverticulitis with the majority of Hinchey class 3 cases, and an overall success rate of $95 \%$ and associated morbidity and mortality of 10 and $1.7 \%$, respectively. A European study found similar trends in comparing laparoscopic lavage to traditional resection with primary anastomosis or end colostomy, with a mortality of $4 \%$ for lavage and $10 \%$ for resection and a complication rate of nearly half for laparoscopic lavage and drainage [46]. While the initial retrospective analyses and case studies involving laparoscopic lavage and drainage trend toward its use as a safe alternative to the initial management of acute complicated diverticulitis, further evidence is required to recommend this modality.

\section{Laparoscopic Versus Open Colon Resection}

Laparoscopic surgery for elective colectomy in diverticular disease is an option that has been shown to have equivalent mortality and complication rates, decreased morbidity, decreased wound infections, and decreased ileus when compared to open resection [47-50]. Given the benefits in an elective setting there is increasing interest in utilizing laparoscopic techniques in the acute/emergent setting of complicated diverticulitis, both for minimally invasive Hartmann's procedure and resection with primary anastomosis. A recent retrospective analysis of the American College of Surgeons National Surgical Quality Improvement Program database suggests that a laparoscopic approach to Hartmann's procedure does not significantly decrease morbidity or mortality when compared to open technique in the patients with complicated diverticulitis [51]. Another recent retrospective analysis of the Nationwide Inpatient Sample examining outcomes of emergent open versus laparoscopic resection found similar findings, with no significant difference in mortality, a high conversion rate to an open procedure of $55 \%$, decreased length of stay of $\sim 1$ day and decreased number of ostomies created in the laparoscopic group, and no cost savings [52•]. The decreased length of stay and decreased rate of ostomy creation may be secondary to selection bias in the previously mentioned retrospective study. While there is an abundance of literature supporting a minimally invasive approach to elective colectomies, there is still a lack of evidence to suggest a benefit in the emergent setting of patients with Hinchey class 3 or 4 diverticulitis. The available evidence suggests that outcomes in minimally invasive and open colectomies in the emergent settings are equivocal, and at this time the approach recommended depends on surgeon comfort level; however, additional studies are needed. 
Fig. 1 Decision-making algorithm for the management of Hinchey class 3 and 4 diverticulitis

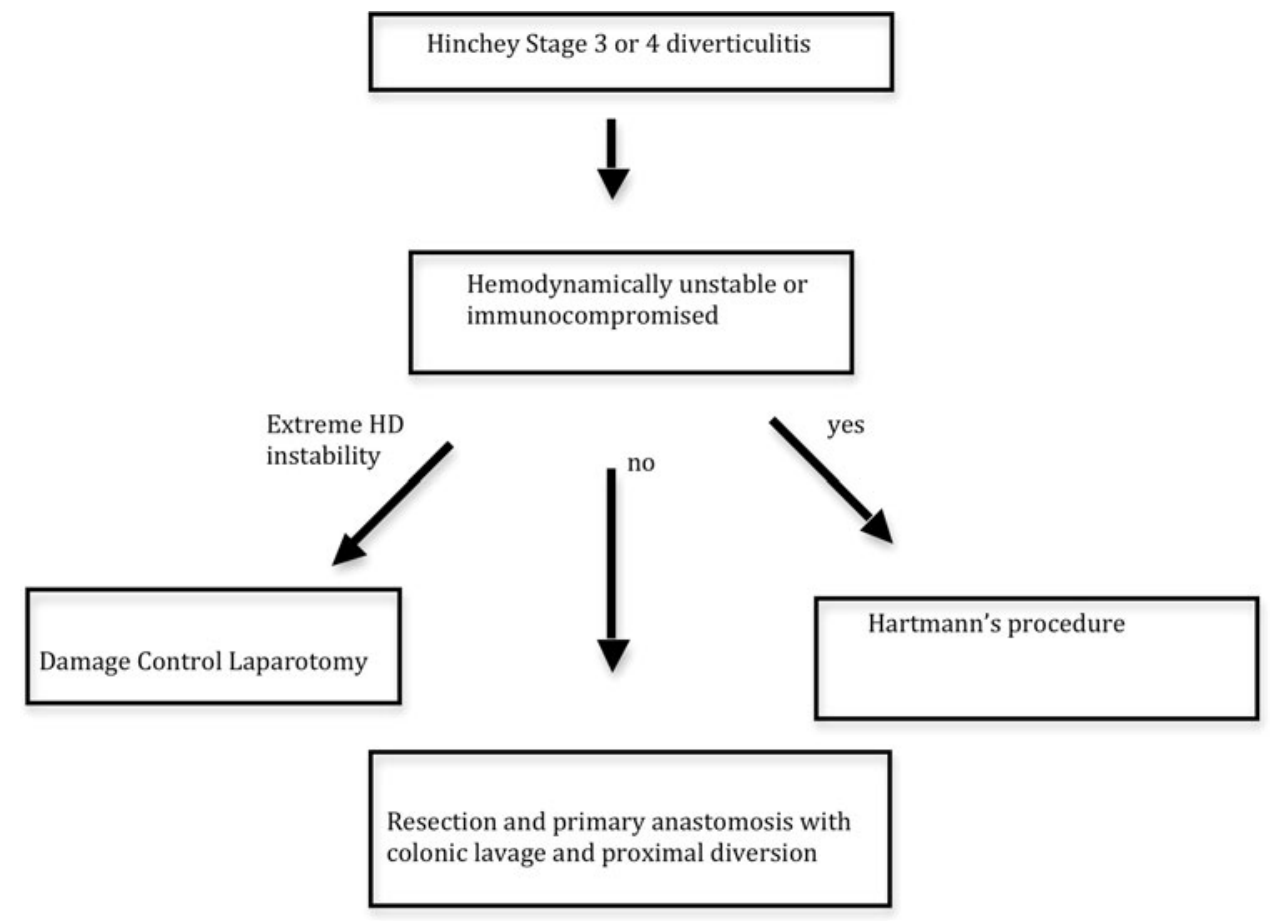

\section{Damage Control Laparotomy}

Damage control laparotomy is a term borrowed from the trauma literature, which refers to performing a truncated operation in especially hemodynamically unstable patients, and transfer to the ICU with temporary abdominal closure and, if necessary, intestinal discontinuity for resuscitation and correction of physiologic parameters [53-55]. Initially described for those patients with catastrophic abdominal injuries and hemorrhage, in order to prevent the mortality associated with the cycle of acidosis, hypothermia, and coagulopathy, this approach has been suggested as an alternative to the above operations in those patients with profound physiologic abnormalities and hemodynamic compromise [56-60]. Utilizing damage control laparotomy in the unstable Hinchey 3 and 4 diverticulitis patient involves an emergent laparotomy with resection of the pathologic colon (with no anastomosis or ostomy during the initial operation), peritoneal lavage, and temporary abdominal closure. This allows the patient to undergo the shortest operative course with source control so that the patient can be transferred to the ICU for necessary resuscitation. The patients are then brought back to the OR within 24-48 $\mathrm{h}$ for reconstruction and closure once the patient's overall physiology has improved.

\section{Conclusions}

The management of fulminant diverticulitis (Hinchey 3 and 4) has evolved significantly since the original three-step procedure of diversion, resection, and reversal, and is continuing to evolve. Currently there are four major options for the management of Hinchey class 3 and 4 diverticulitis: Hartmann's procedure (lap or open), resection with primary anastomosis \pm diverting ostomy (lap or open), laparoscopic washout and drainage, and damage control laparotomy. Hartmann's procedure has traditionally been the standard of care for complicated diverticulitis. However, there is a growing body of evidence supporting resection and primary anastomosis as the standard of care in most cases, with decreased mortality and morbidity, decreased complications, and avoidance of risk of a permanent ostomy. The use of on-table colonic lavage and proximal diversion are highly recommended with primary anastomosis. The Hartmann's procedure, however, seems to be a prudent choice in patients who are hemodynamically unstable due to the shorter operative time. Additionally for those patients that are extremely unstable, a damage control laparotomy may be the best option. Laparoscopic lavage and drainage, while being an attractive option, cannot be recommended at this time, as there is insufficient evidence to support its use over the other options that achieve source control. This is in agreement with the American Society of Colon and Rectal Surgeons's practice parameters for sigmoid diverticulitis, which state that "in urgent or emergent cases as a minimum resection and diversion are generally required" [61]. Concerning minimally invasive colon resections for Hinchey class 3 and 4 diverticulitis, as there is not yet sufficient evidence to show any benefit or disadvantage over open techniques, the decision should remain at the surgeon's comfort level and 
indications for the procedure. Our proposed algorithm based on available evidence for the management of fulminant diverticulitis is seen in Fig. 1. Further investigation, especially into the roles of laparoscopic lavage and drainage and minimally invasive colon resections in the emergent setting, will no doubt continue the evolution of the management of fulminant diverticulitis.

\section{Compliance with Ethics Guidelines}

Conflict of Interest Edward Kwon, T. Browder, and John Fildes declare that they have no conflicts of interest.

Human and Animal Rights and Informed Consent This article does not contain any studies with human or animal subjects performed by any of the authors.

\section{References}

Papers of particular interest, published recently, have been highlighted as:

- Of importance

-. Of major importance

1. Painter NS, Burkitt DP. Diverticular disease of the colon: a deficiency disease of Western civilization. $\mathrm{Br}$ Med $\mathrm{J}$. 1971;2(5759):450-4.

2. Painter NS, Burkitt DP. Diverticular disease of the colon, a 20th century problem. Clin Gastroenterol. 1975;4(1):3-21.

3. Parks TG. Natural history of diverticular disease of the colon. Clin Gastroenterol. 1975;4(1):53-69.

4. Mäkelä J, Kiviniemi H, Laitinen S. Prevalence of perforated sigmoid diverticulitis is increasing. Dis Colon Rectum. 2002;45(7):955-61.

5. Stollman N, Raskin JB. Diverticular disease of the colon. Lancet. 2004;363(9409):631-9.

6. Sarin S, Boulos PB. Long-term outcome of patients presenting with acute complications of diverticular disease. Ann R Coll Surg Engl. 1994;76(2):117-20.

7. Beck DE, Karulf RE. Colonic diverticulosis and diverticular hemorrhage. Clin Coln Rectal Surg. 2004;17(3):195-204.

8. Young-Fadok TM, Roberts PL, Spencer MP, Wolff BG. Colonic diverticular disease. Curr Probl Surg. 2000;37:457-514.

9. Ambrosetti P, Jenny A, Becker C, Terrier TF, Morel P. Acute left colonic diverticulitis: compared performance of computed tomography and water-soluble contrast enema: prospective evaluation of 420 patients. Dis Colon Rectum. 2000;43(10):1363-7.

10. Werner A, Diehl SJ, Farag-Soliman M, Düber C. Multi-slice spiral CT in routine diagnosis of suspected acute left-sided colonic diverticulitis: a prospective study of 120 patients. Eur Radiol. 2003;13(12):2596-603.

11. Biondo S, Borao JL, Millan M, Kreisler E, Jaurrieta E. Current status of the treatment of acute colonic diverticulitis: a systematic review. Colorectal Dis. 2011;14(1):e1-11.

12. Hinchey EJ, Schaal PGH, Richards GK. Treatment of perforated diverticular disease of the colon. Adv Surg. 1978;12:85-108.

13. Wong WD, Wexner SD, Lowry A, Vernava A 3rd, Burnstein M, Denstman F, Fazio V, Kerner B, Moore R, Oliver G, Peters W, Ross T, Senatore P, Simmang C. Practice parameters for the treatment of sigmoid diverticulitis-supporting documentation.
The Standards Task force. The American Society of Colon and Rectal Surgeons. Dis Colon Rectum. 2000;43(3):290-7.

14. Smithwick RH. Experiences with the surgical management of diverticulitis of the sigmoid. Ann Surg. 1942;115:969-85.

15. Lockhart-Mummery JP. Late results of diverticulitis. Lancet. 1938;1938(2):1401-4.

16. Schwesinger WH, Page CP, Gaskill HV, Steward RM, Chopra S, Strodel WE, Sirinek KR. Operative management of diverticular emergencies. Arch Surg. 2000;135(5):558-63.

17. Masoomi H, Buchberg BS, Magno C, Mills SD, Stamos MJ. Trends in diverticulitis management in the United States from 2002 to 2007. Arch Surg. 2011;146(4):400-6.

18. Aydin HN, Tekkis PP, Remzi FH, Constantinides V, Fazio VW. Evaluation of the risk of a nonrestorative resection for the treatment of diverticular disease: the Cleveland Clinic diverticular disease propensity score. Dis Colon Rectum. 2006;49(5):629-39.

19. Cirocchi R, Trastulli S, Desiderio J, Listorti C, Boselli C, Parisi A, Giuseppe N, Liu L. Treatment of Hinchey stage III-IV diverticulitis: a systematic review and meta-analysis. Int J Colorectal Dis. 2013;28(4):447-57.

20. Banerjee S, Leather AJ, Rennie JA, et al. Feasibility and morbidity of reversal of Hartmann's. Colorectal Dis. 2005;7(5):454-9.

21. Maggard MA, Zingmond D, O'Connell JB, et al. What proportion of patients with an ostomy (for diverticulitis) get reversed? Am Surg. 2004;70(10):928-31.

22. Roque-Castellano C, Marchena-Gomez J, Hemmersbach-Miller $\mathrm{M}$, et al. Analysis of the factors related to the decision of restoring intestinal continuity after Hartmann's procedure. Int J Colorectal Dis. 2007;22(9):1091-6.

23. Salem L, Flum DR. Primary anastomosis or Hartmann's procedure for patients with diverticular peritonitis? A systematic review. Dis Colon Rectum. 2004;47(11):1953-64.

24. • Tadlock MD, Karamanos E, Skiada D, Inaba K, Talving P, Senagore A, Demetriades D. Emergency surgery for acute diverticulitis: which operation? A national surgical quality improvement program study. J Trauma Acute Care Surg 2013;74(6):1385-1391. This is a recent query of the NSQIP database demonstrating the equivalence in mortality and surgical site infections for patients who underwent resection and primary anastomosis in comparison to those that received the Hartmann's procedure.

25. Vermeulen J, Coene PP, Van Hout NM, et al. Restoration of bowel continuity after surgery for acute perforated diverticulitis: should Hartmann's procedure be considered a one-stage procedure? Colorectal Dis. 2009;11(6):619-24.

26. Belmonte C, Klas JV, Perez JJ, et al. The Hartmann procedure: first choice or last resort in diverticular disease? Arch Surg. 1996;131(6):612-5 discussion 616-617.

27. - Antolovic D, Reissflder C, Ozkan T, Galindo L, Buchler MW, Koch M, Weitz J. Restoration of intestinal continuity after Hartmann's procedure-not a benign operation. Are there predictors for morbidity? Langenbecks Arch Surg 2011;396(7):989-996. This is a recent study demonstrating the morbidity associated with reversal of the Hartmann's procedure.

28. Perkins JD, Shield CF, Chang FC, et al. Acute diverticulitis: comparison of treatment in immunocompromised and nonimmunocompromised patients. Am J Surg. 1984;148(6):745-8.

29. Tyau ES, Prystowsky JB, Joehl RJ, et al. Acute diverticulitis: a complicated problem in the immunocompromised patient. Arch Surg. 1991;126(7):858-9.

30. Richter S, Lindemann W, Kollmar O, et al. One-stage sigmoid colon resection for perforated sigmoid diverticulitis (Hinchey stages III and IV). World J Surg. 2006;30(6):1027-32.

31. Wigmore SJ, Duthie GS, Young IE, et al. Restoration of intestinal continuity following Hartmann's procedure: the Lothian experience 1987-1992. Br J Surg. 1995;82(1):27-30. 
32. Curran TJ, Borzotta AP. Complications of primary repair of colon injury: literature review of 2,964 cases. Am J Surg. 1999;177(1):42-7.

33. Conrad JK, Ferry KM, Foreman ML, et al. Changing management trends in penetrating colon trauma. Dis Colon Rectum. 2000;43(3):466-71.

34. Zmora O, Mahanjna A, Bar-Zakai B, Rosin D, Hershenko D, Moshe S, Krausz MM, Ayalon A. Colon and rectal surgery without mechanical bowel preparation: a randomized prospective trial. Ann Surg. 2003;237(3):363-7.

35. Bucher P, Gervaz P, Soravia C, Mermillod B, Erne M, Morel P. Randomized clinical trial of mechanical bowel preparation versus no preparation before elective left-sided colorectal surgery. Br J Surg. 2004;92(4):409-14.

36. Sasaki LS, Allaben RD, Golwala R, et al. Primary repair of colon injuries: a prospective randomized study. J Trauma. 1995;39(5): 895-901.

37. Gonzalez RP, Merlotti GJ, Holevar MR. Colostomy in penetrating colon injury: is it necessary? J Trauma. 1996;41(2):271-5.

38. Murray JJ, Schoetz DJ Jr, Coller JA, et al. Intraoperative colonic lavage and primary anastomosis in nonelective colon resection. Dis Colon Rectum. 1991;34(7):527-31.

39. Stewart J, Diament RH, Brennan TG. Management of obstructing lesions of the left colon by resection, on-table lavage, and primary anastomosis. Surgery. 1993;114(3):502-5.

40. Ulrich A, Seiler C, Rahbari N, Weitz J, Buchler MW. Diverting stoma after low anterior resection: more arguments in favor. Dis Colon Rectum. 2009;52(3):412-8.

41. • Gawlick U, Nirula R. Resection and primary anastomosis with proximal diversion instead of Hartmann's: evolving the management of diverticulitis using NSQIP data. J Trauma 2012;72(4) 807-814. This paper utilizes the widely recognized and large NSQIP database to provide evidence for the safety of usage of primary anastomosis versus the Hartmann's procedure in perforated diverticulitis.

42. Constantinides VA, Heriot A, Remzi F, et al. Operative strategies for diverticular peritonitis: a decision analysis between primary resection and anastomosis versus Hartmann's procedures. Ann Surg. 2007;245(1):94-103.

43. • Oberkofler CE, Rickenbacher A, Raptis DA, et al. A multicenter randomized clinical trial of primary anastomosis or Hartmann's procedure for perforated left colonic diverticulitis with purulent or fecal peritonitis. Ann Surg 2012;256(5): 819-827. This study represents the first randomized clinical trial demonstrating the benefit of primary anastomosis with diversion over the Hartmann's procedure in perforated diverticulitis.

44. O'Sullivan GC, Murphy D, O'brian MG, Ireland A. Laparoscopic management of generalized peritonitis due to perforated colonic diverticula. Am J Surg. 1996;171(4):432-4.

45. Toorenvliet BR, Swank H, Schoones JW, Hamming JF, Bemelman WA. Laparoscopic peritoneal lavage for perorated colonic diverticulitis: a systematic review. Colorectal Dis. 2010;12(9):862-7.

46. Rogers A, Collins D, O'Sullivan GC, Winter D. Laparoscopic lavage for perforated diverticulitis: a population analysis. Dis Colon Rectum. 2012;55(9):932-8.
47. Klarenbeek BR, Veenhof AA, Bergamaschi R, et al. Laparoscopic sigmoid resection for diverticulitis decreases major morbidity rates: a randomized control trial: short-term results of the sigma trial. Ann Surg. 2009;249(1):39-44.

48. Dwivedi A, Chahin F, Agrawal S, et al. Laparoscopic colectomy versus open colectomy for sigmoid diverticular disease. Dis Colon Rectum. 2002;45(10):1309-14 discussion 14-5.

49. Lawrence DM, Pasquale MD, Wasser TE. Laparoscopic versus open sigmoid colectomy for diverticulitis. Am Surg. 2003;69(6): 499-503 discussion 503-504.

50. Cirochi R, Farinella E, Trastulli S, Sciannameo F, Audisio RA. Elective sigmoid colectomy for diverticular disease. Laparoscopic versus open surgery: a systematic review. Colorectal Dis. 2011;14(6):671-83.

51. Turley R, Barbas A, Lidsky M, Mantyh C, Migaly J, Scarborough JE. Laparoscopic versus open Hartmann procedure for emergency treatment of diverticulitis: a propensity-matched analysis. Dis Colon Rectum. 2013;56(1):72-82.

52. - Rea JD, Herzig DO, Diggs BS, Cone MM, Kim CL. Use and outcomes of emergent laparoscopic resection for acute diverticulitis. Am J Surg 2012;203(5):639-643. This retroactive review of the nationwide inpatient sample demonstrates that while urgent laparoscopic resection decreases the length of stay, there is a high conversion rate and no difference in mortality with no cost benefit compared to open procedures in the emergent treatment of diverticulitis.

53. Kashuk JL, Moore EE, Millikan JS, Moore JB. Major abdominal vascular trauma: a unified approach. J Trauma. 1982;22(8):672-9.

54. Stone H, Strom PR, Mullins RJ. Management of the major coagulopathy with onset during laparotomy. Ann Surg. 1983; 197(5):532-5.

55. Burch JM, Ortiz VB, Richardson RJ, Martin RR, Mattox KL, Jordan GL Jr. Abbreviated laparotomy and planned reoperation for critically injured patients. Ann Surg. 1992;215(5):476-84.

56. Moore FA, Moore EE, Cothren-Burlew C, et al. Western trauma association critical decisions in trauma: management of complicated diverticulitis. J Trauma Acute Care Surg. 2012;73(6):1365-71.

57. Kafka-Ritsch R, Birkfellner F, Perathoner A, Raab H, et al. Damage control surgery with abdominal vacuum and delayed bowel reconstruction in patients with perorated diverticulitis Hinchey III/IV. J Gastrointest Surg. 2012;16(10):1915-22.

58. Stawicki SP, Brooks A, Bilski T, Scaff D, Gupta R, Schwab CW, Gracias VH. The concept of damage control: extending the paradigm to emergency general surgery. Int J Care Inj. 2008;39(1): 93-101.

59. Lamme B, Boermeester MA, Reitsma JB, Mahler CW, Obertop H, Gouma DJ. Meta-analysis of relaparotomy for secondary peritonitis. Br J Surg. 2002;89(12):1516-24.

60. van Ruler O, Mahler CW, Boer KR, Reuland EA, Gooszen HG, Opmeer BC, de Graaf PW, Lamme B, Gerhards MF, Steller EP, et al. Comparison of on-demand versus planned relaparotomy strategy in patients with severe peritonitis. JAMA. 2007;298(8):865-72.

61. Wong WD, Wexner SD, Lowry A, et al. Practice parameters for the treatment of sigmoid diverticulitis-supporting documentation. Dis Colon Rectum. 2000;43(3):290-7. 